\title{
A promoção das mulheres no espaço social como efeito da normalização da maternidade e da infância
}

\author{
The promotion of women in social space as an effect of the \\ regulation of motherhood and childhood
}

\author{
Ana Laura Godinho Lima \\ Professora da Escola de Artes, Ciências e Humanidades/Universidade de São Paulo. \\ alglima@usp.br
}

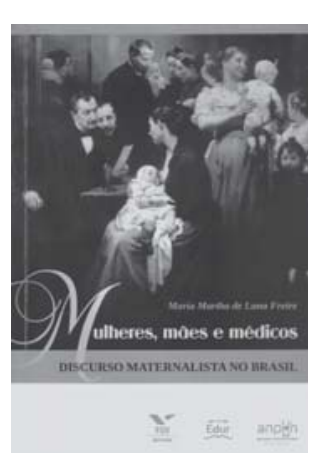

FREIRE, Maria Martha de Luna. Mulheres, mães e médicos: discurso maternalista no Brasil. Rio de Janeiro: Editora FGV, 2009. 264p. $A_{\text {e médicos: discurso maternalista no Brasil, de Maria Martha de }}^{\text {o contrário do que tantas vezes acontece, a obra Mulheres, mães }}$ Luna Freire, cumpre mais do que promete. Sua investigação, abrangente e rigorosa, proporciona contribuições importantes à história da puericultura, da infância e da família no Brasil, assim como aos estudos de gênero. Talvez a principal contribuição seja mostrar que a normalização da maternidade, por meio da difusão dos princípios da higiene infantil, não resultou apenas em maior submissão das mulheres ao poder masculino mas, ao contrário, teve como um de seus efeitos mais importantes o de alargar os horizontes da atuação feminina no espaço social. A pesquisa da autora revela que as mulheres das primeiras décadas do século XX não foram simplesmente coagidas a renunciar aos seus próprios saberes tradicionais para obedecer às orientações ditadas pelos médicos. Procurando acompanhar o processo de modernização dos costumes nos centros urbanos, as feministas decidiram instruir-se em matéria de puericultura e acatar grande parte das recomendações médicas por iniciativa própria, pois enxergaram no exercício esclarecido da função materna uma grande oportunidade de ampliar sua participação na esfera pública. Como bem demonstra a autora, por meio da análise dos discursos veiculados em duas revistas femininas da década de 1920, a higienização da maternidade e da infância não foi imposta às mulheres pelos pediatras puericultores, mas resultou de uma aliança entre médico e mãe, a qual se revelou atrativa para ambos. Por meio dela, os pediatras conquistaram credibilidade e reconhecimento profissional, enquanto as mães foram promovidas a protagonistas do desenvolvimento social.

Ao apresentar o volume, a autora afirma que pretende "analisar como se conformou a afinidade eletiva entre mulheres das classes média e alta urbanas e os médicos dedicados à higiene infantil, em torno da valorização da maternidade" (p.15). Além de evidenciar as condições que favoreceram essa aproximação e examinar seus efeitos para ambas as partes, o livro contribui para a compreensão do processo de emergência da mulher moderna na década de 1920, para o qual a circulação das revistas femininas teve importância decisiva. 
O trabalho de Freire aborda a década de 1920, considerada a Belle Époque das revistas, e elege dois periódicos como fontes principais: Vida Doméstica (Rio de Janeiro, 1920-1963) e Revista Feminina (São Paulo, 1914-1936). No período indicado, ler revistas era uma prática julgada moderna e, segundo a autora, as revistas femininas selecionadas tinham como missão declarada "ensinar a mulher a ser mulher" (p.26) e ajudar a leitora a compreender a si própria. Sendo assim, muitos dos textos veiculados nesses periódicos eram simultaneamente recreativos e pedagógicos. Dirigindo-se às leitoras de classe média e alta que viviam no meio urbano, as revistas funcionavam como manuais da mulher moderna comercializados em fascículos. Procuravam orientar a leitora em meio às tensões vividas no universo identitário feminino. Em grande parte, tratava-se, já naquela época, de tentar responder à atualíssima questão: será possível conciliar o papel da mulher como mãe e esposa ao exercício profissional? No livro Mulheres, mães e médicos, o material das revistas levantado pela autora revela-se fascinante. À medida que vão sendo apresentados exemplos de capas, artigos, anúncios e orientações, o leitor é remetido ao universo feminino da época, suas preocupações, anseios, conflitos e exigências, que nos parecem ora arcaicas "Se teu esposo se afastar de ti, espera-o. Se tarda em voltar, espera-o; ainda mesmo que te abandone, espera-o! Porque tu não és somente a sua esposa; és, ainda, a honra do seu nome" (Revista Feminina, citada na p.80) -, ora atuais - "Um bebê de boa saúde é a alegria de sua mãe. O vosso bebê terá boa saúde se o alimentardes ao seio"(anúncio de Ovomaltine na Revista Feminina, citada na p.105). Em suas considerações, a autora mostra que as revistas femininas constituem uma fonte privilegiada para a compreensão da cultura feminina de maneira geral. São, além disso, um recurso precioso de que os pesquisadores dispõem para aproximar-se da cultura da maternidade higiênica ou científica que ainda é a nossa e que, tendo surgido na passagem do século XIX para o XX, ganhou um grande impulso na década de 1920, por meio dos periódicos destinados às mulheres.

Antes de passar ao exame das questões diretamente relacionadas à maternidade, Maria Martha Freire explora, no segundo capítulo do livro, a tensão entre as diferentes concepções em disputa acerca do lugar da mulher na sociedade. A autora afirma que as revistas femininas, ao expressar diferentes pontos de vista a respeito do movimento feminista "dentro de uma margem relativamente ampla de divergências" (p.43), ofereciam-se como espaço de debate e reflexão para as leitoras sobre modos distintos de se portar socialmente. Num período caracterizado como sendo de transição, a própria modernidade era percebida ora como progresso - quando associada ao desenvolvimento tecnológico e científico - ora como degradação dos costumes, quando se tratava de caracterizar a vida mundana feminina no meio urbano. As atividades sociais que afastavam a mulher de casa, tais como passeios, visitas e chás com as amigas chegavam a ser percebidas como ameaças à família e, consequentemente, à própria nação. Sendo assim, a mulher moderna condenável era aquela que vivia fora de casa e se ocupava pouco do lar, do marido e dos filhos, pondo em risco a ordem social. A mulher moderna bem-educada, interessada em cuidar da saúde e da beleza segundo as orientações dos especialistas, disposta a organizar racionalmente seu lar e sua rotina e preocupada com a economia e a higiene domésticas era sempre louvada.

Os mesmos textos que valorizavam a participação das mulheres no espaço público afirmavam que a sua missão mais elevada era a maternidade. Os autores que manifestavam 
sua convicção de que por meio do voto as mulheres poderiam participar no grande trabalho de reformar o mundo afirmavam também que, de todo modo, sua contribuição mais importante continuava sendo como mães que preparavam em casa os futuros cidadãos da pátria (p.43).

Quanto à difícil conciliação entre vida profissional e maternidade, todas as alternativas vislumbradas nas revistas indicavam a primazia da dimensão materna. Uma das possibilidades seria tratar a maternidade como se fosse uma profissão, a profissão feminina por excelência. Por outro lado, valorizavam-se os esforços femininos para exercer um ofício e contribuir para o orçamento doméstico, em vez de viver comodamente à custa do marido. Como decorrência, a disposição para o trabalho era admirada como uma qualidade da boa esposa. Nessa modalidade discursiva, a mulher esbanjadora do dinheiro do marido era referida como uma figura antiga, a ser superada na modernidade. Considerava-se que um caminho adequado para as mulheres era exercer um ofício identificado com a maternidade; logo, ser professora ou enfermeira, ou ainda, atuar como educadora sanitária, eram algumas das opções 'naturais' para as mulheres das classes média e alta. A filantropia era também um modo de inserção no mundo profissional altamente valorizado, mas não deixava de significar o exercício público da função materna, por meio do qual as mulheres seguiam cuidando de outros, geralmente de outras crianças. Já para as mulheres pobres, o trabalho mais recorrente era o serviço doméstico remunerado, tido como um mal necessário, que punha em risco a vida familiar.

Um dos aspectos centrais do discurso veiculado nas revistas diz respeito à ideia de que, na modernidade, a mulher precisava aprender a ser mulher, ou seja, a ser uma boa esposa e uma boa mãe. Esse aprendizado envolvia o conhecimento de informações científicas a respeito do próprio corpo, sua saúde e sua beleza; da casa, sua organização e sua higiene; das crianças, seu desenvolvimento e educação. Esperava-se da mulher moderna que fosse capaz de definir cientificamente o cardápio de sua família, que empregasse racionalmente seu tempo e os recursos disponíveis, de modo a fazer render seu próprio trabalho, assim como o salário do seu marido, para proporcionar as melhores condições de vida possíveis aos seus filhos e ao seu cônjuge. Naturalmente, não se tratava de renunciar ao próprio bem-estar, mas de fazer corresponder a felicidade própria à de sua família. Havia publicações especialmente dedicadas a orientar as mulheres nesse sentido, tais como o manual $O$ lar feliz, o qual "ensinava todos os passos para a utilização racional do tempo no desempenho do trabalho doméstico, a fim de que, ao final do dia, a dona de casa pudesse receber seu marido com o semblante tranquilo e um sorriso nos lábios" (p.88).

O terceiro capítulo do livro mostra como se procurou transformar as práticas de cuidados com os bebês por meio da divulgação dos princípios da puericultura. Analisa mais detidamente as seções das revistas femininas assinadas por médicos e outros especialistas, bem como as propagandas que anunciavam produtos para facilitar a vida da mulher-mãe moderna, a leitora educada, que buscava se orientar pelos conhecimentos científicos da área. Nessa parte, destaca-se a importância social e política atribuída à criança - promovida a cidadão do futuro - e à mãe, responsável por sua preparação. Freire nos lembra que na década de 1920 o patriotismo era percebido como um valor moderno e não conservador, conforme veio a ser considerado mais tarde. Segundo os especialistas que contribuíam 
para as revistas Vida Doméstica e Revista Feminina, a mulher moderna compreendia o valor patriótico de sua dedicação aos filhos, pois dela dependiam o vigor físico e o caráter dos 'soldados da pátria'. Para formá-los, além das orientações sobre os cuidados diários, relativos à alimentação e à higiene, recomendava-se a educação física desde bebês, indicando-se os exercícios, a maneira correta de realizá-los e o número de repetições, que variavam de acordo com a idade da criança.

Entre os fatores que favoreceram a aliança entre médicos e mães em torno da higienização da infância e da família, Freire menciona o aumento da eficácia dos remédios a partir da década de 1920, o que contribuiu para que a medicina e a puericultura conquistassem maior credibilidade entre as mães. A participação da indústria farmacêutica no processo de construção da maternidade científica precisa ser considerada. A defesa da educação feminina também foi um ponto de convergência que, segundo a autora, aproximava os articulistas das revistas, fossem médicos, intelectuais, religiosos, educadores ou feministas. Todos defendiam a criação de escolas para mulheres e mães. A educação feminina, além dos elementos já mencionados, relativos aos cuidados com o lar e a alimentação da família, incluía conhecimentos sobre como disciplinar a criança sem recorrer aos castigos físicos, como identificar o temperamento de cada filho, com vistas a intervir de maneira adequada em sua formação. Esperava-se, portanto, que a mãe pudesse atuar como fiscal do desenvolvimento infantil, de modo a ser capaz de perceber a tempo possíveis desvios ou distúrbios. A mãe seria ainda a primeira professora e, consequentemente, deveria ser capaz de proporcionar às crianças leituras que favorecessem a formação do caráter, brincadeiras educativas e brinquedos apropriados à idade do filho. Tendo em vista que a boa educação deveria começar já no início da vida, era preciso disciplinar o contato físico entre a mãe e o bebê. O colo da mãe, por exemplo, era considerado um mimo prejudicial. O bebê higienizado deveria permanecer em seu berço, isolado. Conforme observa Freire (p.202), o berço pode ser interpretado um "símbolo exemplar da proposta de individualização higiênica do corpo infantil". Dada a complexidade das atribuições maternas, julgava-se imprescindível que a mãe cuidasse pessoalmente dos filhos e do lar. Caso houvesse criados para auxiliá-la, esses deveriam ser mantidos sob estrita vigilância.

Em Mulheres, mães e médicos: discurso maternalista no Brasil, o tema da alimentação infantil mereceu um capítulo exclusivo, o que se justifica pela centralidade do tema nos textos de puericultura, sobretudo no tocante à amamentação. Esse tópico merece atenção especial ainda por ter sido o ponto mais sensível na aproximação entre mães e médicos, aquele que exigiu especial boa vontade de parte a parte, de modo a ser possível conciliar as convicções médicas à conveniência das mulheres.

Os especialistas afirmavam que a maior causa da mortalidade infantil eram os problemas digestivos associados a erros dietéticos, por conseguinte acreditavam que "na acertada alimentação da infância está a chave do futuro da nação" (Roca Puig, citado na p.206). Entendiam que o meio mais sensato de evitar a desgraça era recorrer sempre ao aleitamento materno nos primeiros meses de vida da criança. Tais especialistas buscavam superar o problema combatendo-o em duas frentes: por um lado, solicitavam apoio do poder público para as mulheres pobres, na forma de serviços para a distribuição de leite e de orientações 
às mães necessitadas; por outro lado, divulgavam conhecimentos de puericultura entre as mulheres mais favorecidas, tais como as leitoras das revistas femininas.

Na década de 1920, os pediatras dispunham já de numerosos estudos científicos que permitiam comprovar a superioridade do leite materno em relação a todas as outras alternativas para a alimentação do bebê. Recorriam à ciência e à estatística para conferir legitimidade a seus discursos em prol da amamentação, mas, como nos mostra Freire em sua análise dos textos publicados nas revistas femininas, não deixavam de empregar também exortações morais e até religiosas com o mesmo propósito. Afirmava-se que o leite da mãe era por direito da criança e, portanto, a amamentação era uma obrigação da mãe. Outras estratégias de convencimento eram a promessa de maior felicidade e beleza para as mães que amamentavam e a ponderação de que a amamentação era mais prática para a mulher do que a alimentação artificial, uma vez que dispensava a necessidade de lavar e ferver mamadeiras, calcular as quantidades da mistura e controlar a temperatura do leite. Segundo o discurso médico, o leite de peito estava sempre pronto para ser oferecido, na formulação e na temperatura exatas para atender ao apetite do bebê. É curioso observar que, embora os médicos afirmassem que a amamentação era um ato determinado pela própria natureza, entendiam que as mulheres precisavam de instrução e de técnica para conseguir realizá-la a contento. Esse aprendizado incluía a higiene dos seios, o posicionamento correto do bebê para mamar, a duração da mamada e o intervalo entre as refeições. Sendo assim, a simplicidade do aleitamento materno era anunciada para logo depois ser negada nos mesmos textos.

De todo modo, era preciso admitir que nem todas as mães amamentavam e, segundo sugere Freire, muito provavelmente grande parte delas não o fazia. Diante dessa constatação, restava aos autores procurar justificar cientificamente as dificuldades enfrentadas por tantas mulheres em amamentar e procurar com elas as melhores soluções. Na impossibilidade de contar com o leite da mãe, havia divergências entre os médicos sobre qual seria a melhor alternativa, se a ama de leite ou a mamadeira. No entanto, era certo para todos eles que as duas opções requeriam acompanhamento médico minucioso. Os doutores reprovavam o costume bastante difundido na época de recorrer-se às amas de leite, por considerá-lo atrasado e arriscado, tanto para a saúde física como para a educação moral das crianças. Mesmo assim, já que tantas famílias optavam por essa solução, consentiam em instruir as mulheres sobre os critérios que deveriam ser levados em conta em sua seleção. De maneira análoga, os médicos chamavam atenção para os grandes riscos da alimentação artificial mas, por fim, acabavam concedendo às leitoras orientações sobre como realizá-la. Uma vez que, apesar de todas as advertências, a alimentação artificial era muito praticada, era melhor que fosse realizada de acordo com as recomendações médicas do que sem elas.

O capítulo sobre a alimentação do lactente é de fato aquele que melhor permite perceber como se foi estabelecendo a relação entre mãe e pediatra. Mais do que apenas dominação masculina, tratava-se, muitas vezes, de uma relação de reciprocidade: as solicitações médicas eram atendidas porque satisfaziam as necessidades femininas, de sorte que mesmo essas recomendações não foram simplesmente impostas às mulheres, mas muitas vezes solicitadas por elas, tendo em vista a sua própria conveniência. Além disso, o recurso ao médico 
representava para as mães uma porta de acesso ao mundo da ciência, conferindo-lhes o status de mulheres instruídas e modernas, capazes de conduzir racionalmente a alimentação e a vida de seus filhos e de sua família.

Enfim, o belo livro de Maria Martha de Luna Freire nos mostra que a higienização da maternidade não foi apenas mais uma variação da imposição masculina de uma condição submissa às mulheres, obrigadas a acatar os diagnósticos e tratamentos prescritos pelos doutores. Freire conclui que, se as mulheres aceitaram ouvir as orientações médicas, foi porque o discurso higiênico sobre a maternidade proporcionou-lhes a oportunidade de ocupar uma nova posição social. A mulher-mãe moderna tornou-se personagem decisiva para garantir um futuro mais auspicioso para a nação, pois, conforme se acreditava naquele período, de seu esclarecimento e de sua dedicação dependiam as qualidades dos novos cidadãos da pátria. 